\title{
Preparation, Structure and Optical Properties of Nanoporous Gold Thin Films
}

\author{
Matthew C. Dixon, Thomas A. Daniel, Mitsunori Hieda, Detlef M. Smilgies, Moses H. W. Chan, and
}

David L. Allara

Correspondence to: dla3@psu.edu

\section{A. Top-Down SEM Etch Time Dependence of 80, 400 and $800 \mathrm{~nm} \mathrm{np-Au}$ at 20,000X and 150,000X Magnifications}

Images of 80,400 and $800 \mathrm{~nm}$ films at different etch times are shown in Figures 1 through 5. Magnifications of 20,000 and 150,000 were used to visualize larger scale features and to examine the fine structure of the pores. The images showed the dealloying process to begin immediately after the samples were immersed in $\mathrm{HNO}_{3}$. After one minute in $\mathrm{HNO}_{3}$, features appeared due to $\mathrm{Ag}$ removal from the surface. The pores appeared to coarsen with extended etching and transformed into different structures altogether with long etch times $(60$ and $96 \mathrm{~h})$. For the $80 \mathrm{~nm}$ film after $60 \mathrm{~h}(3600 \mathrm{~min})$, the film's continuity appeared to break down and the resulting structure appeared more like a roughened surface. For the $400 \mathrm{~nm}$ film after $96 \mathrm{~h}$ (5760 min), the cracks visible in the earlier images disappeared and for the $800 \mathrm{~nm}$ film after $96 \mathrm{~h}$ (5760 min) small features formed on the np-Au fingers. In the 400 $\mathrm{nm}$ film images in Figure 3, comparison of images etched for 1500, 3600 and 5760 min revealed that the Au strand size was not changing but the pore size was increasing. This reinforced the observation that $\mathrm{Au}$ was removed from the surface. Large scale cracks varying in length from hundreds of nm were visible in the 400 and $800 \mathrm{~nm}$ thick films that were not visible in the $80 \mathrm{~nm}$ film. The cracks appeared wider in the $800 \mathrm{~nm}$ film. Pores coarsened up to an order of magnitude as the films were etched longer. A variety of different pore sizes could be formed through etching the same thickness alloy for different times. For example, XPS showed that all of the silver was leached out of the $80 \mathrm{~nm}$ alloy in $6 \mathrm{~h}$ (360 min) so samples up until $25 \mathrm{~h}(1500 \mathrm{~min})$ could be used for an application requiring a variety of pore sizes. From the SEM images in Figure 2 the 360 and 1500 minute images show the pores to increase in size by a factor of two. In general, as the thickness of the alloy was increased there became a wider range of pore sizes that were achievable with variable etch time. 

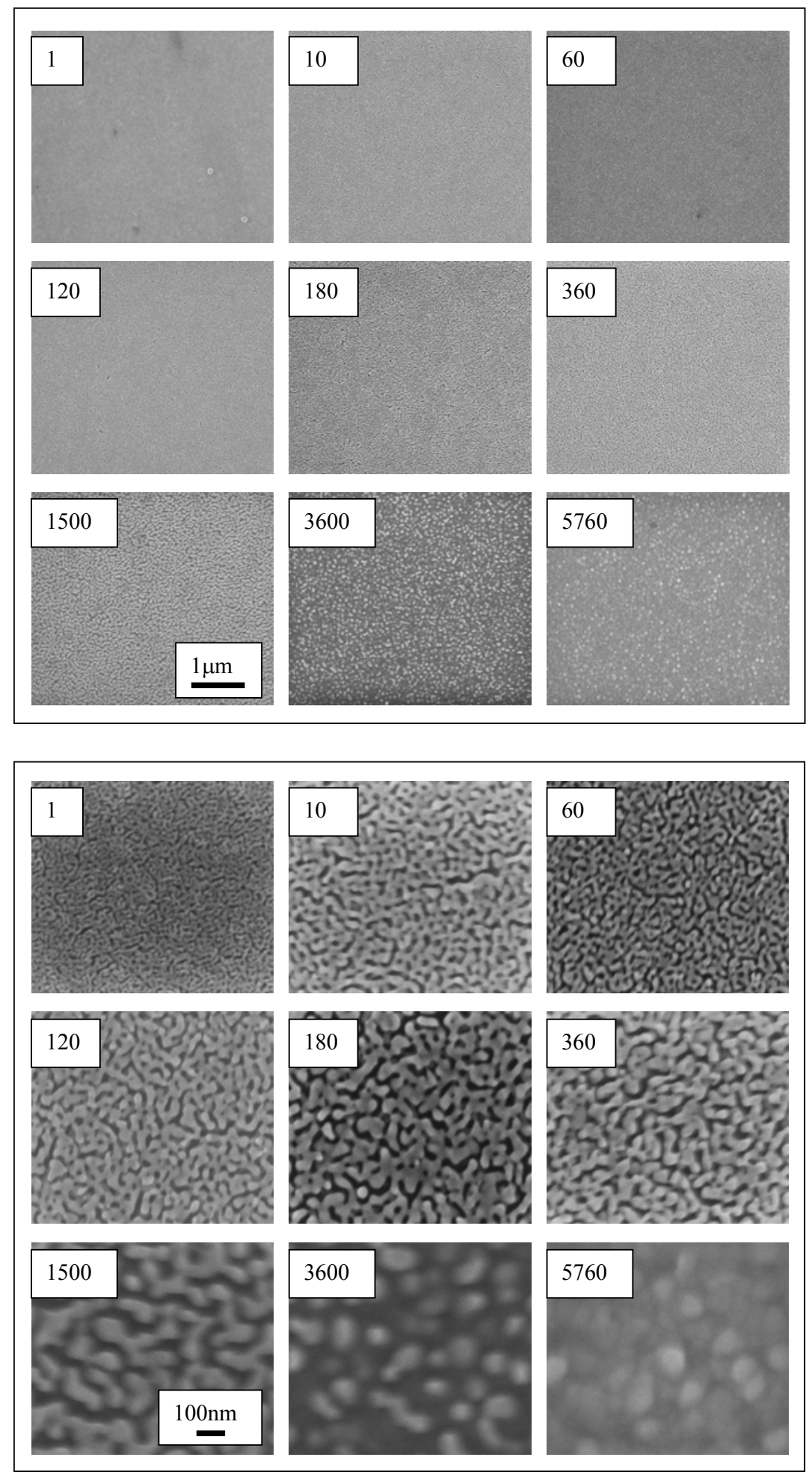

Figure 1. SEM images of $80 \mathrm{~nm} \mathrm{np-}$ $\mathrm{Au}$ films etched for different amounts of time (in minutes) at 20,000X magnification.

Figure 2. SEM images of $80 \mathrm{~nm} \mathrm{np}$ $\mathrm{Au}$ films etched for differing amounts of time (in minutes) at $150,000 \mathrm{X}$ magnification. 


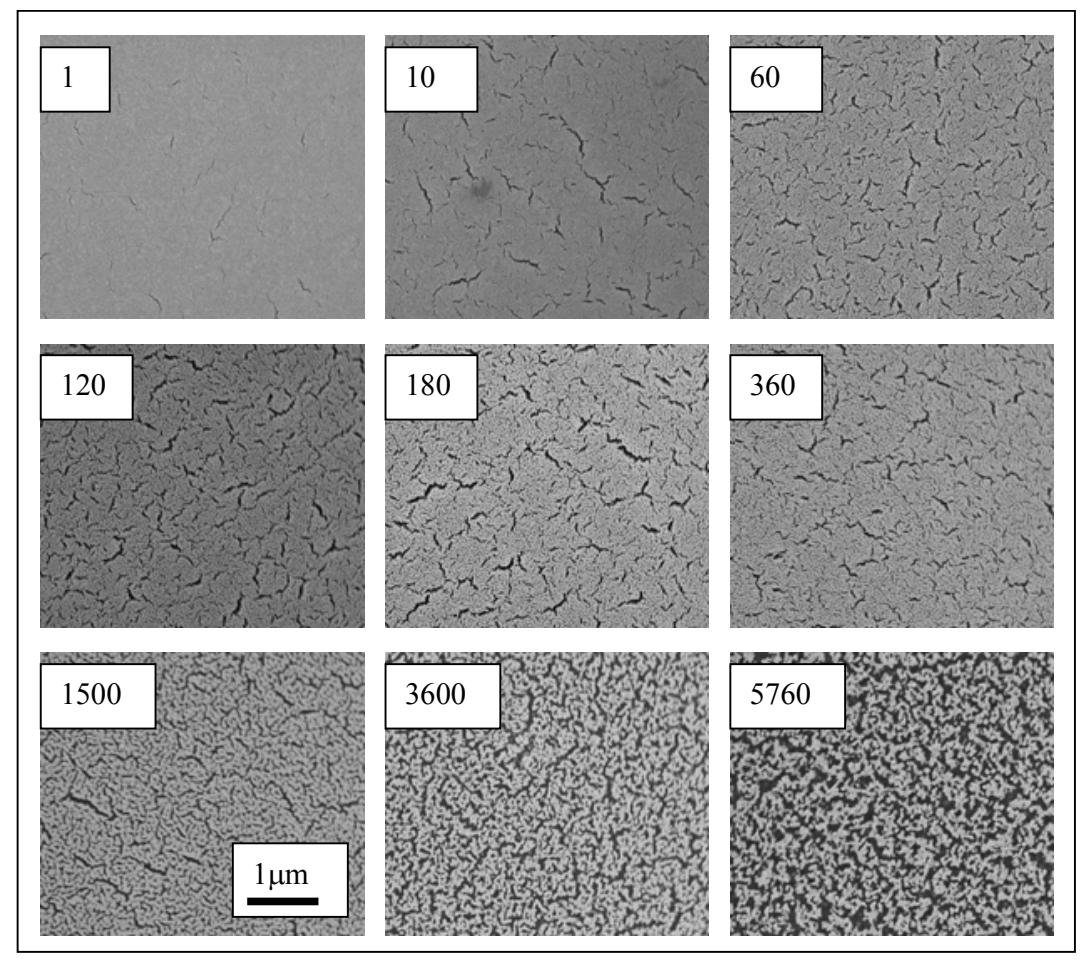

Figure 3. SEM images of $400 \mathrm{~nm} \mathrm{np}-\mathrm{Au}$ films etched for differing amounts of time (in minutes) at $20,000 \mathrm{X}$ magnification.
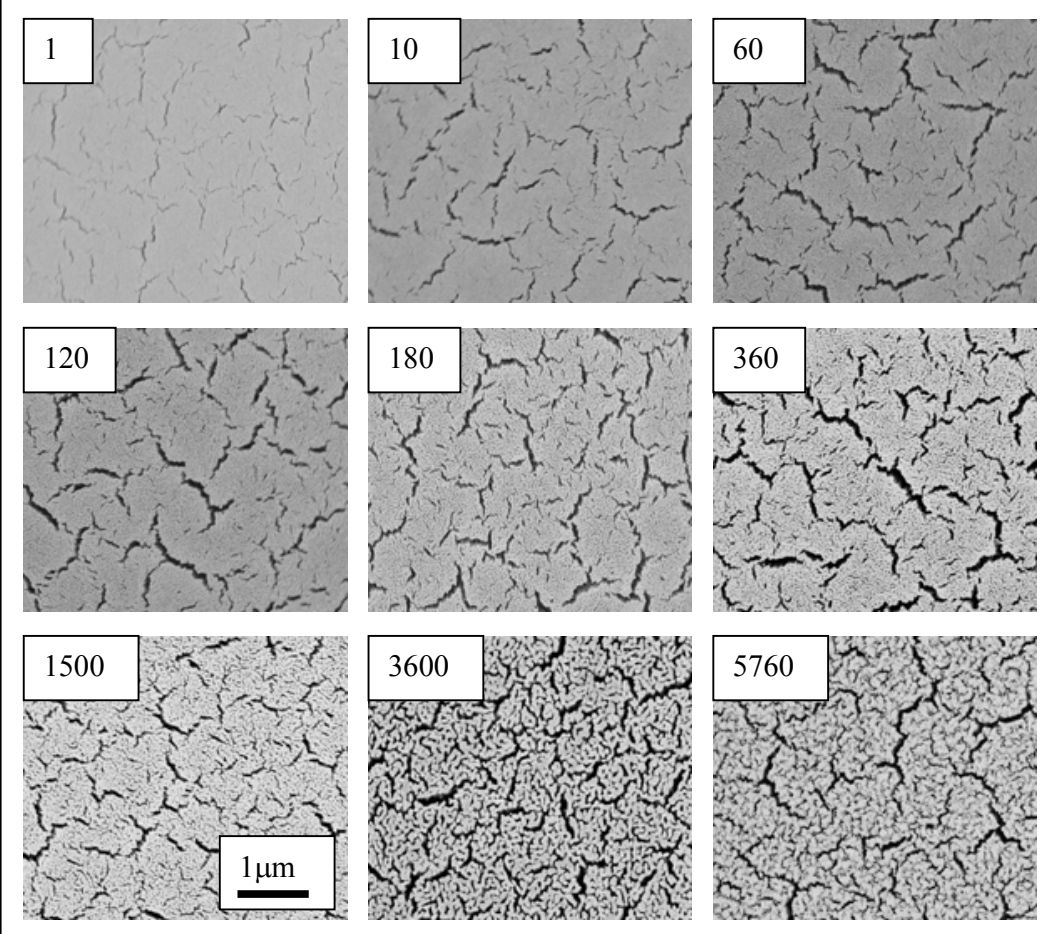

Figure 4. SEM images of $800 \mathrm{~nm} \mathrm{np}-$ $\mathrm{Au}$ films etched for differing amounts of time (in minutes) at $20,000 \mathrm{X}$ magnification. 


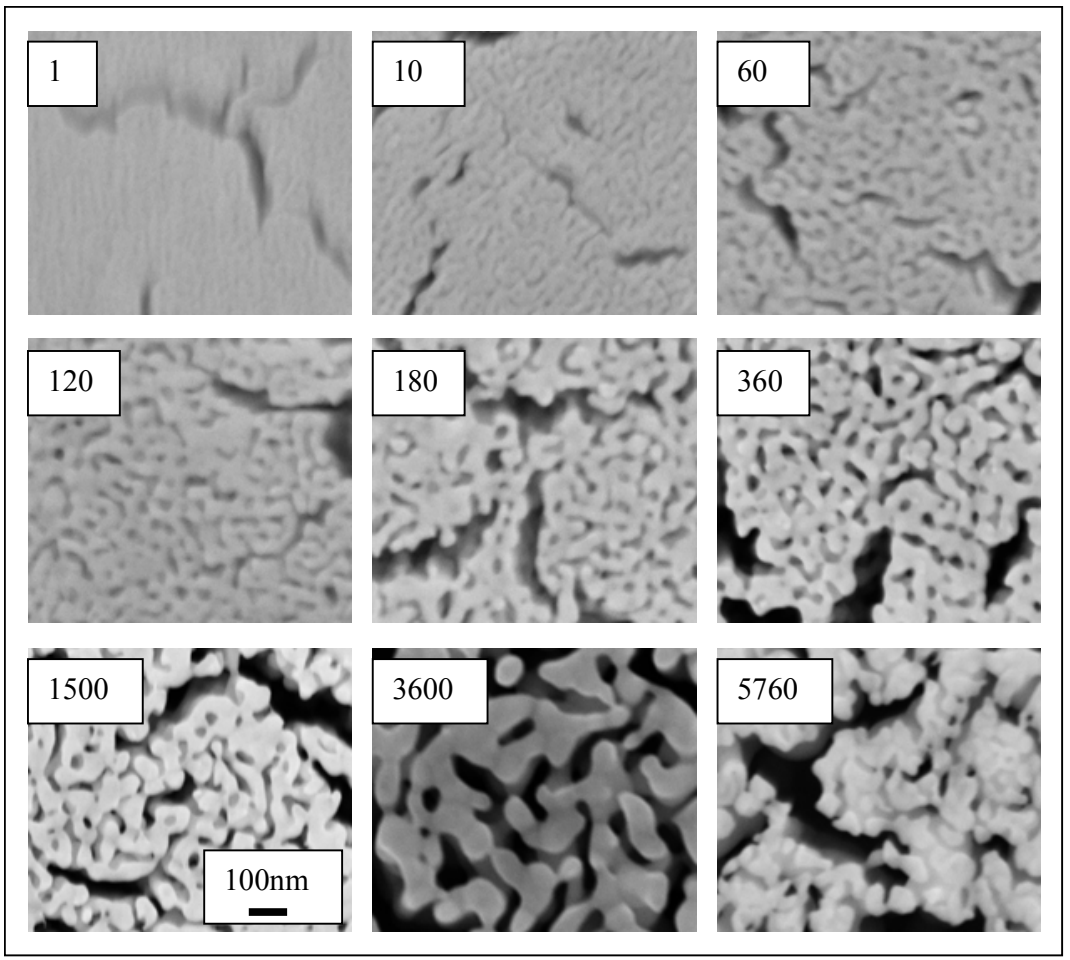

Figure 5. SEM images of $800 \mathrm{~nm} \mathrm{np}$ $\mathrm{Au}$ films etched for differing amounts of time (in minutes) at $150,000 \mathrm{X}$ magnification. 


\section{B. Cross-Section SEM Thickness Dependence for $24 \mathrm{~h}$ Etch Time at 100,000 Magnification}

CSSEM images of various thickness np-Au etched for $24 \mathrm{~h}$ were taken in order to estimate the actual thickness of the films and to get an idea where the transition to bulk np-Au occurs. From the 40, 160, 240, 320, 400, 480, 560, 640, 800, and $1600 \mathrm{~nm}$ thick films in Figure 6, it was evident that the actual thickness of the np-Au films were less than the numbers currently being used to describe the thicknesses. The majority of the measured thicknesses were $\sim 0.9$ times the numbers arbitrarily used to describe the $\mathrm{Ag}_{\mathrm{x}} \mathrm{Au}_{1-\mathrm{x}}$ alloy thickness. Up to $240 \mathrm{~nm}$ in thickness, there did not appear to be much of a 3D structure to the np-Au; rather the surface looked more or less like a roughened version of a flat surface. At $320 \mathrm{~nm}$, the films appeared to take on a bulk np-Au structure with interconnecting pores. The thicknesses of the fingers in the cross section samples did not follow a clear trend since the $400 \mathrm{~nm}$ sample had strands smaller than the $480 \mathrm{~nm}$ and the $800 \mathrm{~nm}$ but larger than the $1600 \mathrm{~nm}$ sample. This indicates that the pore sizes do not follow a trend based on thickness of alloy for a given etch time.

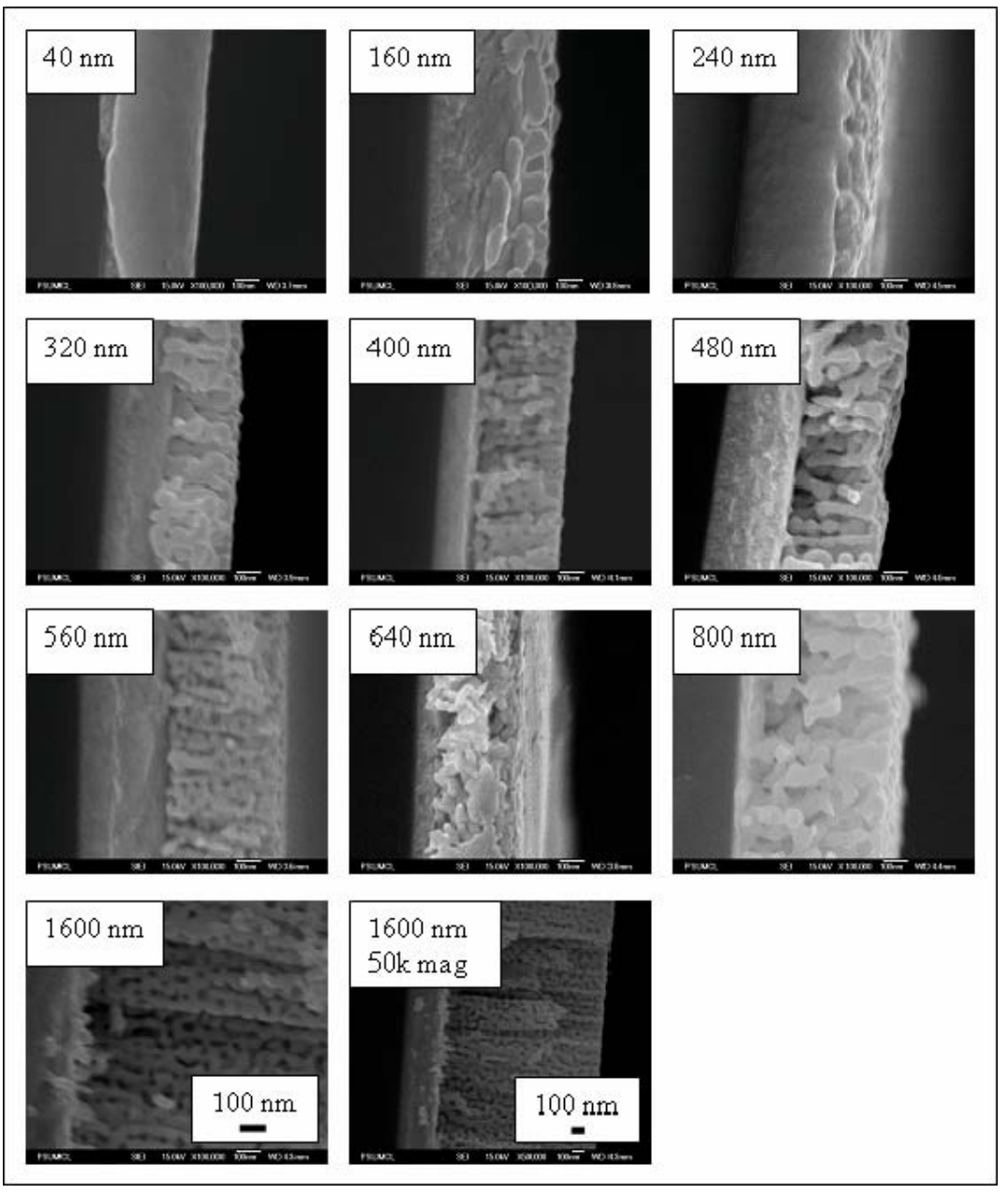

Figure 6. Cross section SEM images of various thickness $\mathrm{np}-\mathrm{Au}$ films formed by etching for $24 \mathrm{~h}$; images $40-1600$ nm taken at $100,000 \mathrm{X}$ magnification and $1600 \mathrm{~nm} 50 \mathrm{k}$ mag at 50,000X 


\section{Surface Area Measurements by Cyclic Voltammetry (CV).}

Measurements were performed in a standard 3-electrode Teflon cell (Pt auxiliary electrode, $\mathrm{Ag} / \mathrm{AgCl} /$ sat'd $\mathrm{KCl}$ reference, $100 \mathrm{mM} \mathrm{KNO}_{3}$ electrolyte) using a Radiometer PGZ100 potentiostat. Polyimide tape masks defined the sample electrode area. CV was recorded at variable rates and capacitance was determined from the slope of linear regression plots of the sums of absolute current $v s$ rate. ${ }^{1}$ Constant current regions of the $\mathrm{CV}$ were chosen in order to ensure that charge-transfer reactions of trace impurities were avoided. The sums of the positive and negative currents of each CV were taken at three points to average out any non ideal polarized electrode behavior. Since for our experimental configuration capacitance is proportional to surface area, the surface areas were calculated by determining the relationship between capacitance and area for a planar electrode.

Table 1. Capacitance of $\mathrm{np}-\mathrm{Au}$ films and corresponding ratios to the geometric surface area. Etch times in hours are given in parenthesis. All capacitance values are the average of at least four measurements. The measurement error was determined to be $\pm 7.61 \mu \mathrm{F} / \mathrm{cm}^{2}$ from the standard deviation of four flat Au capacitances.

\begin{tabular}{c|c|c} 
& & $\begin{array}{l}\text { Ratio of capacitance surface } \\
\text { area to geometric (flat) } \\
\text { Surface Area }\end{array}$ \\
\hline 0 & Capacitance $\left(\mu \mathrm{F} / \mathrm{cm}^{2}\right)$ & 1.00 \\
$400(6)$ & 31.15 & 17.33 \\
$400(24)$ & 530.25 & 10.47 \\
$800(24)$ & 326.03 & 22.67 \\
$800(48)$ & 706.14 & 16.78 \\
$1600(24)$ & 522.64 & 48.76 \\
$1600(48)$ & 1518.91 & 32.98 \\
\hline \multicolumn{2}{c}{} \\
\hline 0 & 1027.40 & 1.00 \\
$(500(?)$ & 21.01 & 17.63
\end{tabular}

$(?)=$ etch time was not recorded but was probably between $12-48 \mathrm{~h}$

The data was separated since they were taken on different days with slightly different concentrations of $100 \mathrm{mM} \mathrm{KNO}_{3}$ 


\section{Ellipsometrically Determined Optical Properties}

Example spectra of $6 \mathrm{~h}$ etched samples at $25^{\circ} \mathrm{C}$ were shown in Figure 7 . Based on the raw data, the calculated dielectric functions and the calculated refractive indices, the thickness of the np-Au film had a large affect on the spectral response. In bulk gold, the interband transition around $~ 500 \mathrm{~nm}$ appears as a valley in the $\Delta$ or $\mathrm{k}$ spectrum and a slope in the $\Psi$ and $\mathrm{n}$ spectrum. These same features appear in the $40 \mathrm{~nm} \mathrm{np}-\mathrm{Au}$ film. This indicates that the films have similar optical characteristics and supports the findings based on SEM images (Fig. 8 main text) that the $40 \mathrm{~nm}$ film does not form an interconnected network of np-Au but more or less a rough surface. The best estimation of the $40 \mathrm{~nm}$ actual thickness was between 0-1 nm from the CSSEM images for a $24 \mathrm{~h}$ etched sample; that amount of material did not appear to form a porous network for the $6 \mathrm{~h}$ etched sample based on ellipsometry. For the $80 \mathrm{~nm}$ sample, the features attributed to the interband transition disappear, but as the thickness was increased to 160 and $400 \mathrm{~nm}$ another feature $\sim 500 \mathrm{~nm}$ appears in the spectrum. The values of the $\mathrm{k}$ spectrum dropped to a minimum as the thickness of the np-Au films approached $160 \mathrm{~nm}$. This indicated that the $160 \mathrm{~nm}$ thick $\mathrm{np}-\mathrm{Au}$ film reached "quasibulk" $\mathrm{np}-\mathrm{Au}$ properties since the amount of light being absorbed by the material did not change dramatically as the thickness was increased to $400 \mathrm{~nm}$. Trends appear reversed in the 160 and $400 \mathrm{~nm}$ thick $\mathrm{n}$ and $\mathrm{k}$ spectra versus the flat Au spectra. For flat Au, there appears a dip in the $\mathrm{k}$ spectrum that has a similar overall trend as the 160 and $400 \mathrm{~nm}$ dip in the $\mathrm{n}$ spectrum. There is also a similar occurrence for the $\mathrm{n}$ spectra of flat Au having the same sloping trend as the 160 and $400 \mathrm{~nm} \mathrm{k}$ spectra. 


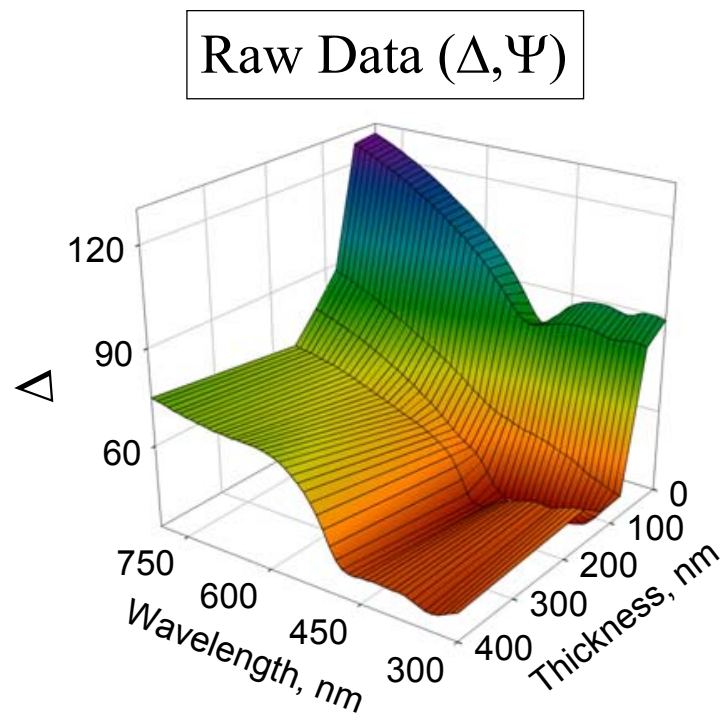

\section{Dielectric Constants $\left(\varepsilon_{1}, \varepsilon_{2}\right)$}
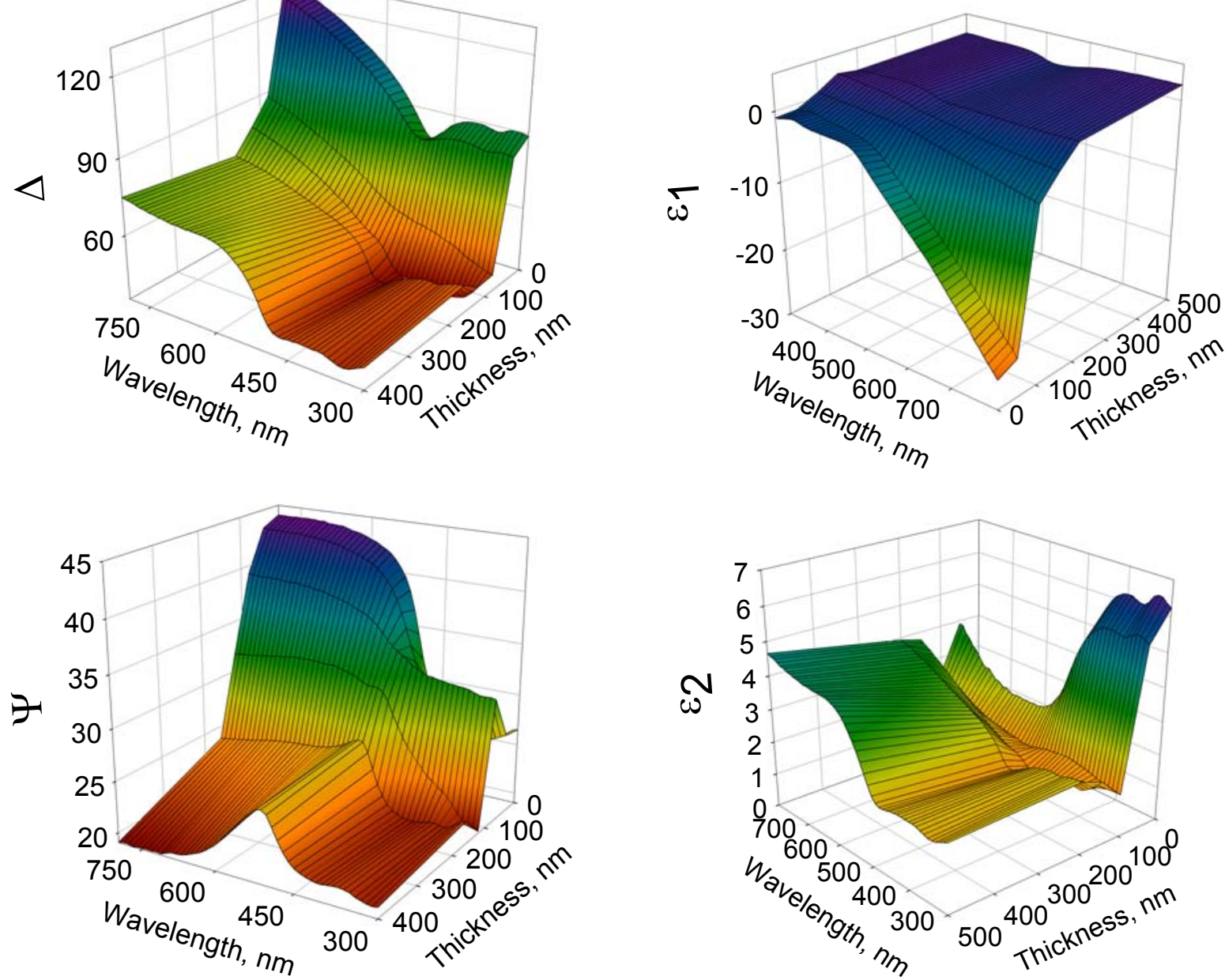


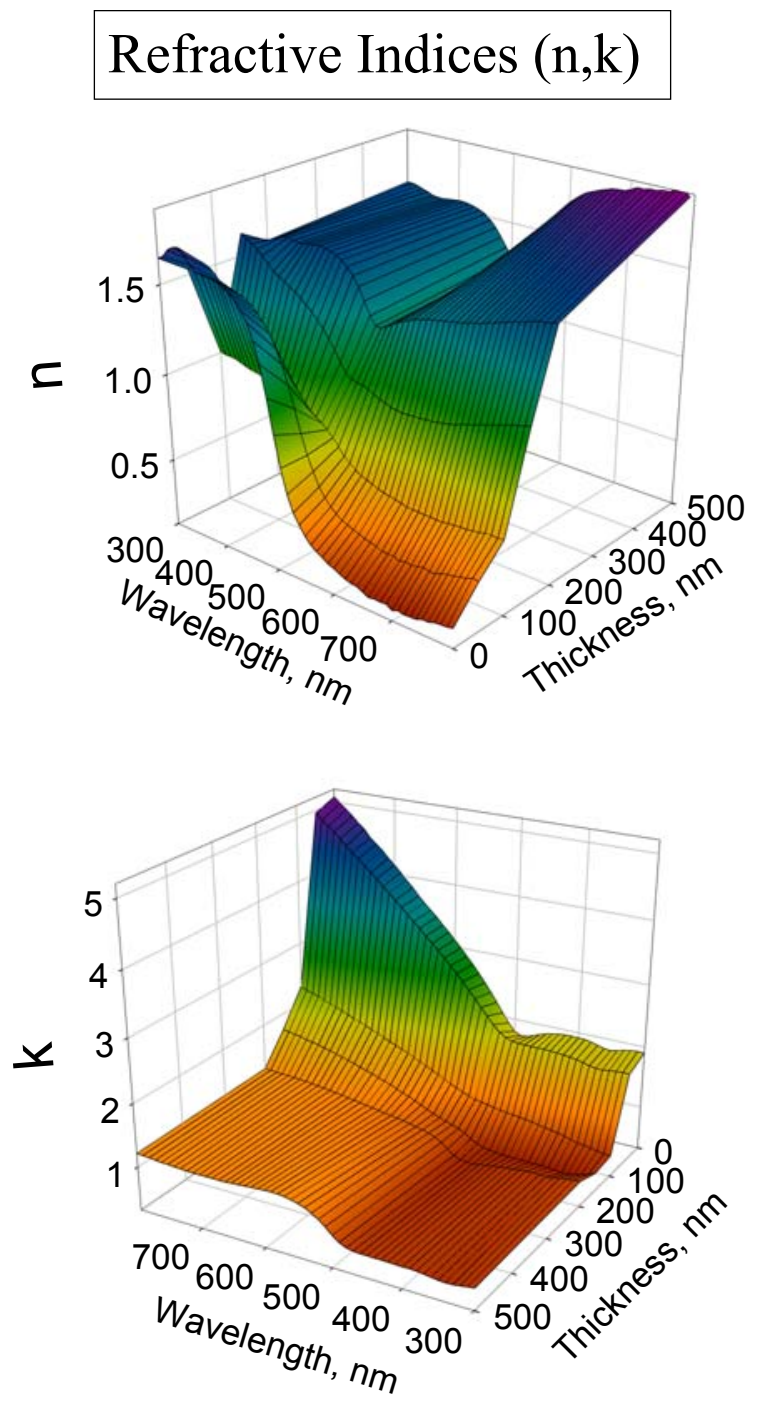

Figure 7. $\operatorname{Raw}(\Delta, \Psi)$ and processed $\left(\varepsilon_{1}, \varepsilon_{2}\right.$ and $\left.\mathrm{n}, \mathrm{k}\right) \mathrm{SE}$ data of $40,80,120,160$, and $400 \mathrm{~nm}$ thick alloy films etched for $6 \mathrm{~h}$. Included for comparison is a bare, standard planar $\mathrm{Au}$ ( $200 \mathrm{~nm}$ thick) film representative of the type used as the substrate for alloy deposition. The main aspect to notice is the variation from typical Au features to the appearance of a new optical transition as thickness increases.

In order to try and understand what effect pore size will have on the optical response of np-Au, samples were etched for different amounts of time and annealed at different temperatures. Variable thickness np$\mathrm{Au}$ was etched for either 6 or $24 \mathrm{~h}$ and annealed at $100^{\circ} \mathrm{C}$ and $200^{\circ} \mathrm{C}$. The $\mathrm{n}$ and $\mathrm{k}$ spectra of the 6 and $24 \mathrm{~h}$ etched samples are compared in Figure 8 . The $24 \mathrm{~h}$ etched series shows the transition from flat $\mathrm{Au}$ to $\mathrm{np}-\mathrm{Au}$ to shift to larger thicknesses probably between $80 \mathrm{~nm}$ and $120 \mathrm{~nm}$. The $\mathrm{k}$ spectrum does not drop to a minimum for the $80 \mathrm{~nm} 24 \mathrm{~h}$ etched sample like it did for the $6 \mathrm{~h}$ etched sample, meaning that light is not absorbed as much in the $24 \mathrm{~h}$ etched sample compared to the $6 \mathrm{~h}$ etched sample. 

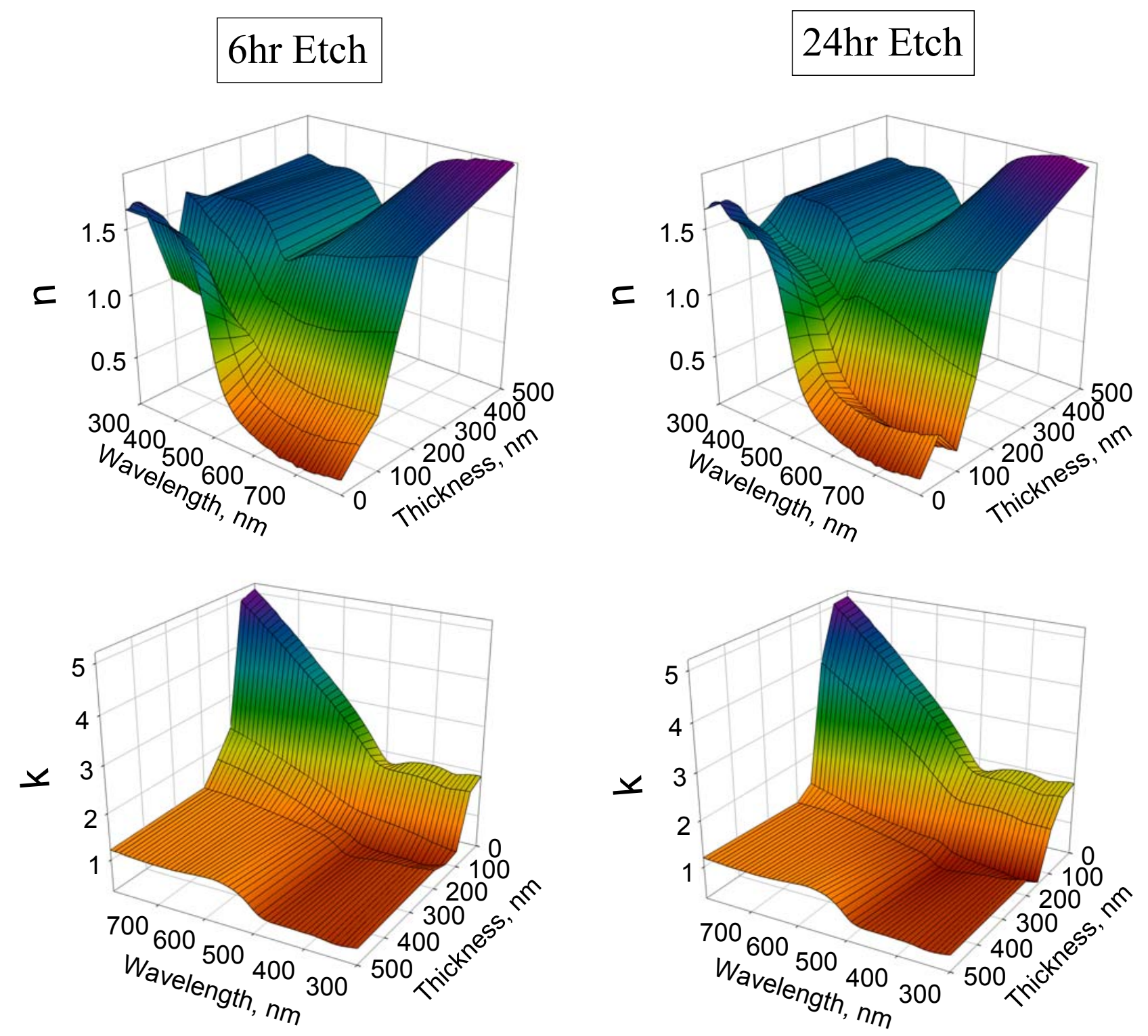

Figure 8. SE derived optical function spectra (n, k) of 40, 80, 120, 160, and $400 \mathrm{~nm}$ thick alloy films etched for 6 and $24 \mathrm{~h}$. Included for comparison is a bare, standard planar Au (200 nm thick) film representative of the type used as the substrate for alloy deposition. The main aspect to notice is the slight variation of the 40,80 and $120 \mathrm{~nm}$ spectra due to increased etch time.

In Figure 9 the variable thickness annealed samples show little change going from $25^{\circ} \mathrm{C}$ to $100^{\circ} \mathrm{C}$. For the $200^{\circ} \mathrm{C}$ set there appears a change in the optical response at the transition from flat $\mathrm{Au}$ to $\mathrm{np}-\mathrm{Au}$ showing up for the $120 \mathrm{~nm}$ thick sample. The appearance of a surface plasmon peak $\sim 500 \mathrm{~nm}$ characteristic for np-Au appeared in the $\mathrm{n}$ spectrum. The peak was broader and shifted lower in intensity relative to the $160 \mathrm{~nm}$ and $400 \mathrm{~nm}$ spectra. Annealed spectra of $24 \mathrm{~h}$ etched np-Au are not shown here, but the data indicated that the $160 \mathrm{~nm}$ spectrum transformed into the $400 \mathrm{~nm}$ spectrum upon annealing at $100^{\circ} \mathrm{C}$, and to a greater extent at $200^{\circ} \mathrm{C}$. In other words, the $160 \mathrm{~nm}$ sample took on optical features resembling the $400 \mathrm{~nm}$ sample upon heating. The other thicknesses did not appear to change within this range of annealing. 

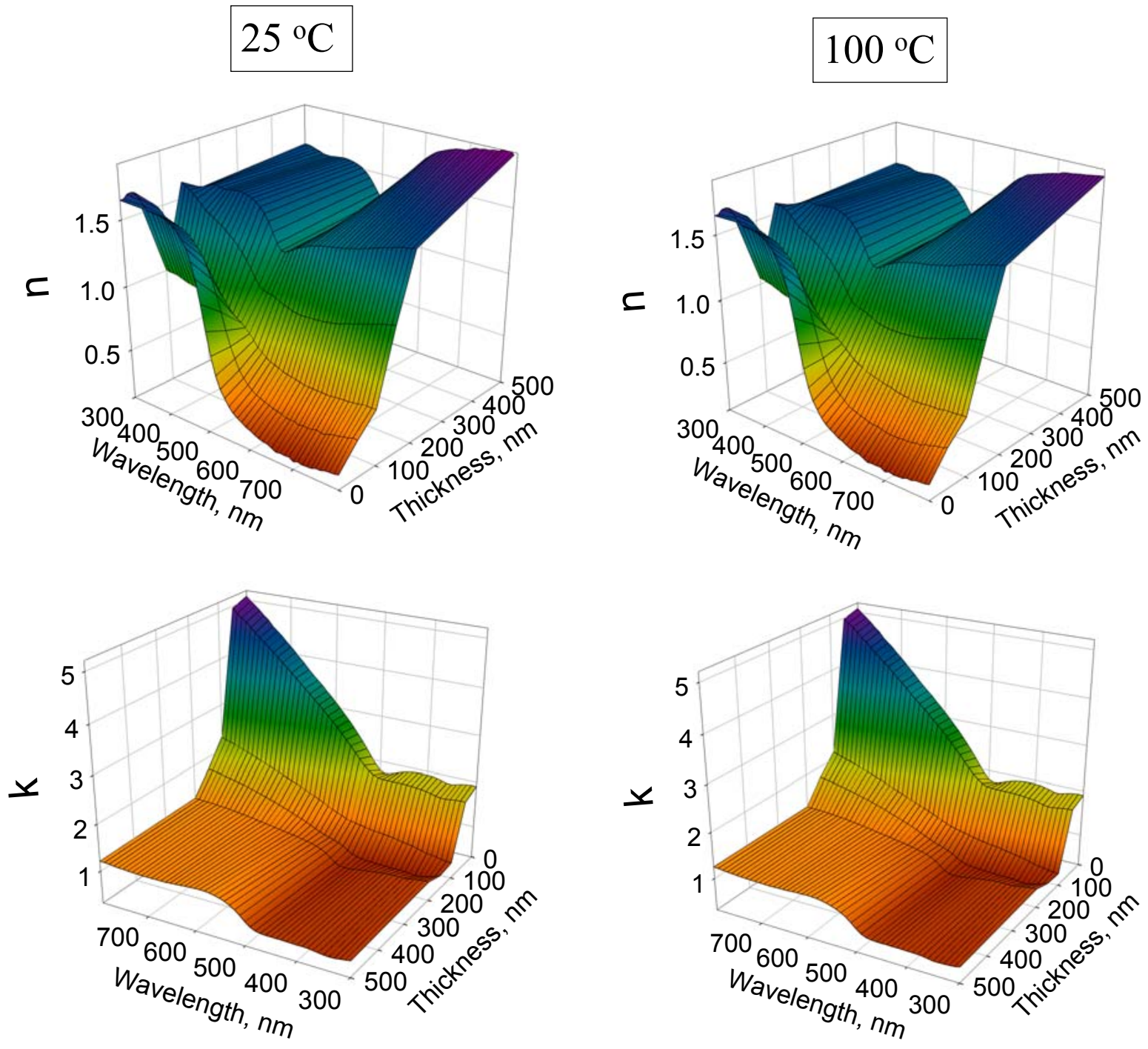


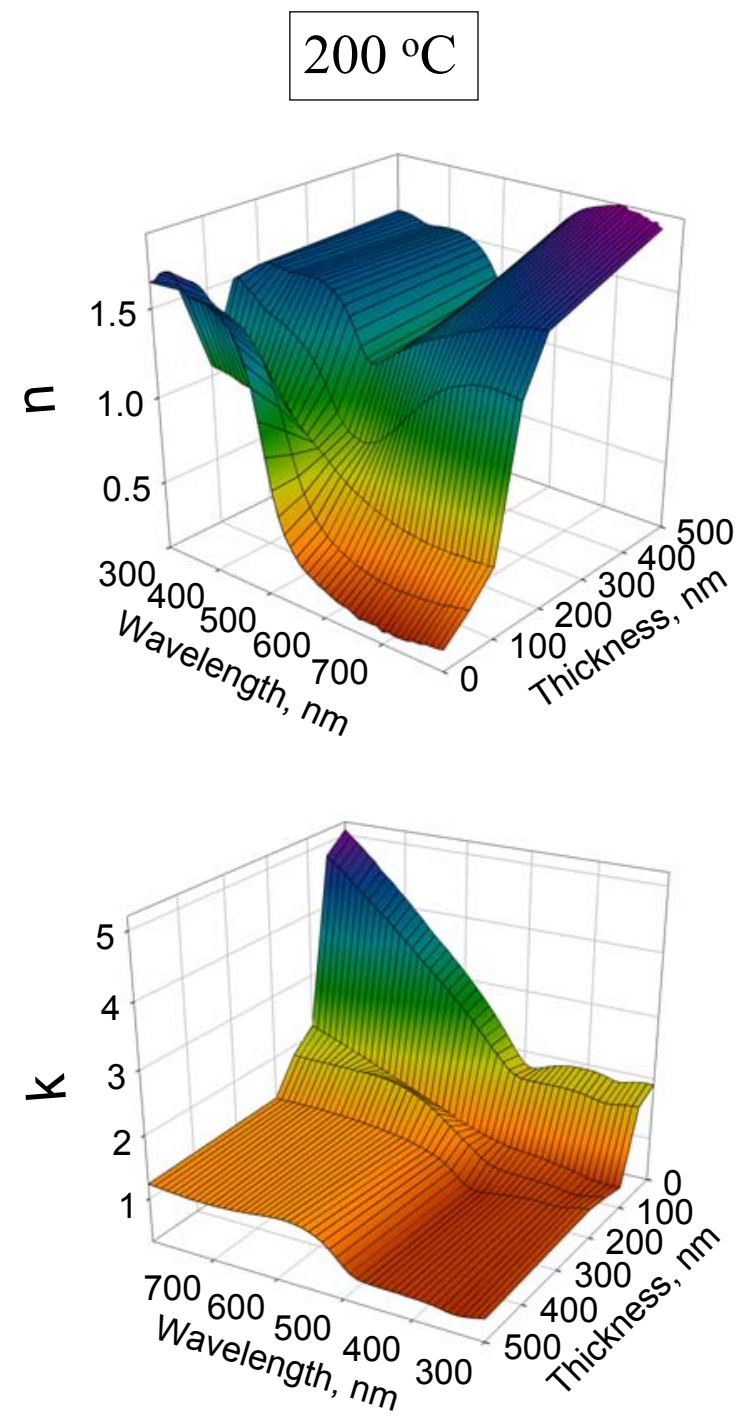

Figure 9. SE derived optical function spectra (n, k) of 40, 80, 120, 160, and $400 \mathrm{~nm}$ thick alloy films etched for $6 \mathrm{~h}$ and annealed at $25{ }^{\circ} \mathrm{C}, 100{ }^{\circ} \mathrm{C}$ and $200{ }^{\circ} \mathrm{C}$ for $10 \mathrm{~min}$. Included for comparison is a bare, standard planar $\mathrm{Au}(200 \mathrm{~nm}$ thick) film representative of the type used as the substrate for alloy deposition. The main aspect to notice is the slight variation of the 80 and $120 \mathrm{~nm}$ spectra due to increased temperature. 


\section{E. Maxwell-Garnett and Bruggeman Effective Medium Theory Calculations}

Briefly, the Maxwell-Garnett theory builds on the Clausius-Mossotti equation: $\frac{\varepsilon-1}{\varepsilon+2}=\frac{1}{3} \sum_{j} N_{j} \alpha_{j} 2,3$ that provides the link between the macroscopic property of the dielectric constant, $\varepsilon$ and the microscopic parameter of polarizability, $\alpha$. For binary systems Maxwell-Garnett ${ }^{4}$ assumed the model for the polarizability with the relation: $\left(\frac{\varepsilon_{M G}-\varepsilon_{2}}{\varepsilon_{M G}+2 \varepsilon_{2}}\right)=f_{1}\left(\frac{\varepsilon_{1}-\varepsilon_{2}}{\varepsilon_{1}+2 \varepsilon_{2}}\right)$ where $\varepsilon_{1}$ and $\varepsilon_{2}$ are the dielectric constants of materials 1 and 2, respectively, $\varepsilon_{\mathrm{MG}}$ is the effective dielectric constant from the Maxwell-Garnett approach and $f_{1}$ is the volume fraction of molecules or inclusions in material 1. The Maxwell-Garnett model assumed a composite material composed of spherical particles that had dimensions small compared to the probing wavelength and that were well separated (i.e. no aggregation effects). ${ }^{5}$ Bruggeman 6 modified the Maxwell-Garnett theory to include volume fractions of each of the components giving: $f_{1}\left(\frac{\varepsilon_{1}-\varepsilon_{B}}{\varepsilon_{1}+2 \varepsilon_{B}}\right)+f_{2}\left(\frac{\varepsilon_{2}-\varepsilon_{B}}{\varepsilon_{2}+2 \varepsilon_{B}}\right)=0$ where $\varepsilon_{1}, \varepsilon_{2}$, and $\varepsilon_{B}$ were the dielectric constants of material 1 and 2 and the effective dielectric constant, respectively. The volume fractions $f_{1}$ and $f_{2}$ were defined as $f_{1}=\frac{V_{1}}{V_{\text {total }}}$ and $f_{2}=\frac{V_{2}}{V_{\text {total }}}$ where $V_{\text {total }}=V_{1}+V_{2}$ with $\mathrm{V}$ representing the volume of the components. The Bruggeman model assumed a random distribution of one component in the other allowing for one continuous medium in another.
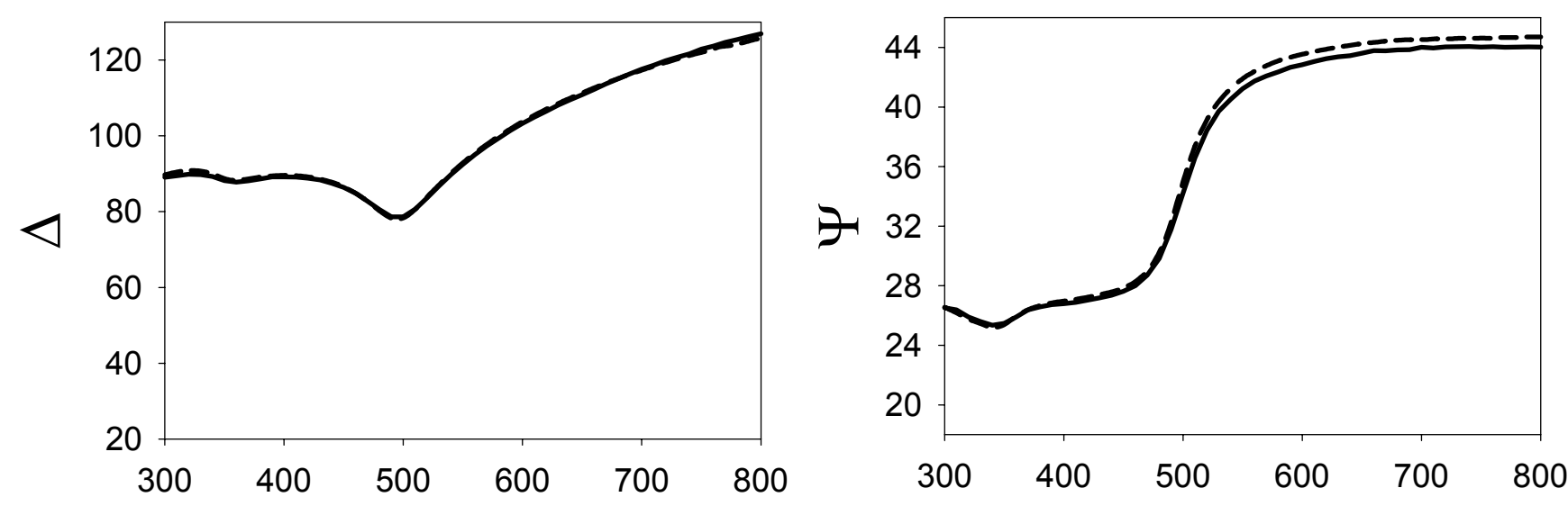

Wavelength, $\mathrm{nm}$

Figure 10. Experimental SE data of flat thermally evaporated Au (straight line) and a 2 medium simulation based on an infinite gold substrate-Air model (dashed line). Au optical constants were taken from Palik. ${ }^{2}$ 
Note that the fit for the $\Psi$ spectrum deviates at longer wavelengths. Attempts were made to improve the fit by including contaminant overlayers and surface roughness but various combinations of these two strategies did not significantly improve the overall global fits. These problems are likely due to small but real deviations of the dielectric function spectra of our vapor deposited gold from the Handbook values used in the simulations.

Table 2. Measured Parameters for EMT Simulations.

Estimated Values

\begin{tabular}{c|c|c|c}
\hline Thick QCM, nm & Thick CSSEM, nm & Void Frac by EDS/XPS & Void Frac by SEM \\
\hline 0 & - & 0 & 1 \\
40 & - & $0.31-0.37$ & - \\
80 & $60-66.6$ & $0.31-0.37$ & - \\
120 & $80-91.6$ & $0.31-0.37$ & - \\
160 & $100-117$ & $0.31-0.37$ & 0.32 \\
400 & $300-333$ & $0.31-0.37$ & 0.322
\end{tabular}

Void fraction by SEM estimated using top down SEM images and ImageJ software

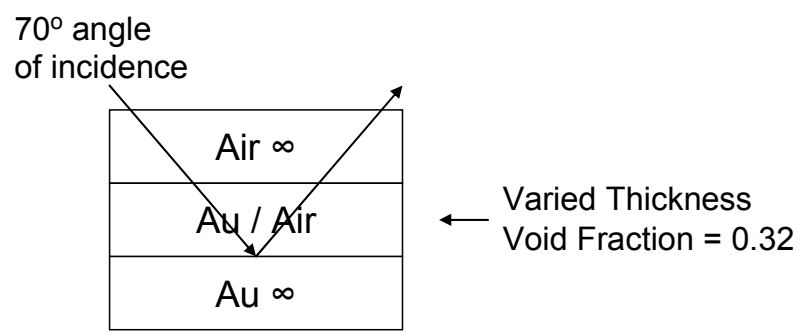

Figure 11. Model for EMT Simulations. 
Wavelength, $\mathrm{nm}$

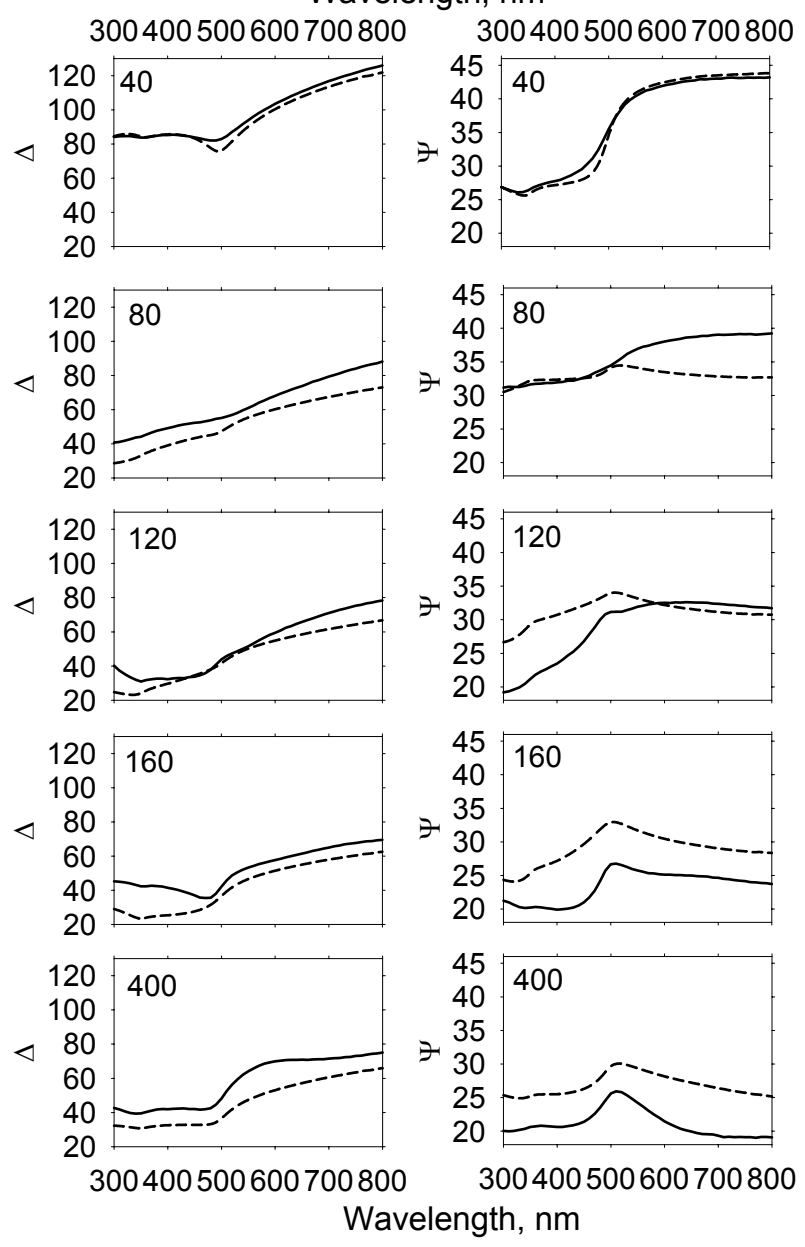

Figure 12. Bruggeman EMT fits to 40, 80, 120, 160 and $400 \mathrm{~nm}$ thick np-Au etched for $6 \mathrm{~h}$.

Simulations were performed according to the text. The dotted lines are simulations and the solid lines are experimental data. The simulations were based on 3 medium model [air / (air-Au composite) / Au] using a composite layer void fraction of 0.32 with thicknesses measured by CSSEM 8 


\section{F. Vibrational mode assignments for the Raman spectra of pure 4- fluorbenzenethiol and the corresponding SAM on np-Au}

Table 3. Peak Assignments of 4-fluorobenzenethiol on $160 \mathrm{~nm} 6$ hour etched np-Au. The mode assignments were made using assignments from literature reports 9 and the notation abbreviations are similar to those used by Varsanyi. 10 The mode descriptions are: $v$, stretch; $\gamma$, out of plane bending; $\beta$, in plane bending; $\pi$, wagging and $\tau$, torsion.

\begin{tabular}{|c|c|c|}
\hline \multicolumn{2}{|c|}{ Frequencies $\left(\mathrm{cm}^{-1}\right)$} & \multirow[b]{2}{*}{ Vibrational Assignment } \\
\hline Bulk & $\mathrm{np}-\mathrm{Au}$ & \\
\hline 253 & & - \\
\hline 329 & & $9 b(b 2), \beta C S$ \\
\hline 373 & 385 & $16 \mathrm{a}(\mathrm{a} 2) \tau \mathrm{CC}$ \\
\hline 419 & & $7 a(a 1), v C S+\beta C C C$ \\
\hline 632 & 625 & 12(a1), vCCC \\
\hline 693 & & $6 a(a 1), \beta C C C+v C S$ \\
\hline 814 & 814 & 11(b1), $\pi \mathrm{CH}$ \\
\hline 832 & & $10 \mathrm{a}(\mathrm{a} 2), \gamma \mathrm{CH}$ \\
\hline 918 & & $\beta \mathrm{SH}$ \\
\hline 1198 & 1077 & vCF \\
\hline 1159 & 1156 & $15(\mathrm{~b} 2), \beta \mathrm{CH}$ \\
\hline 1227 & & - \\
\hline 1493 & 1489 & $19 a(a), v C C+\beta C H$ \\
\hline 1593 & 1589 & $8 a(a 1), v C C$ \\
\hline 2570 & & $v \mathrm{SH}$ \\
\hline 3071 & & 2(a1), vCH \\
\hline
\end{tabular}




\section{References}

1 In the $-200 \mathrm{mV}-+600 \mathrm{mV}$ range, the Au working electrode acted somewhat like an ideal polarized electrode so the behavior at the electrode solution interface was analogous to that of a capacitor. The electrode solution interface can be described by the electrical double layer and at a given potential the electrical double layer can be characterized by a double layer capacitance that is often a function of potential. For example see Bard, A. J.; Faulkner L. R. Electrochemical Methods: Fundamentals and Applications; $2^{\text {nd }}$ Ed. Wiley: New York, 2001.

2 Mossotti, O. F. Mem. Mat. Fis. Modena 1850, 24, 49.

3 Clausius, R. Die Mechanische W. Armtheorie II Vol. 62, Braunschweig, 1897.

4 Maxwell-Garnett, J. C. Philos. Trans. R. Soc. London 1904, 203, 385.

5 Sipe, J. E.; Boyd, R. W. Phys. Rev. A 1992, 46, 1614-1629.

6 Bruggeman, D. A. G. Ann. Phys. Leipzig 1935, 24, 636.

7 Handbook of Optical Constants of Solids; Palik, E. D. Ed., Academic Press, 1985.

8 Note that for the $40 \mathrm{~nm}$ film, the thinnest one studied, a $2.5 \mathrm{~nm}$ thickness yielded the closest fit to the data and altering the void fraction yielded no improvement. Further, an accurate thickness could not be determined by CSSEM and the SEM data suggested that the film eroded upon etching.

9 Joo, T. H.; Kim, M. S.; Kim, K. J. Raman Spectroscopy 1987, 18, 57-60; Futamata, M. J. Phys. Chem. 1995, 99, 11901-11908; Osawa, M.; Matsuda, N.; Yoshii, K.; Uchida, I. J. Phys. Chem. 1994, 98, 12702-12707; Socrates, G. Infrared and Raman Characteristic Group Frequencies; John Wiley \& Sons: Chichester, 2001.

10 Varsanyi, G. Assignments for Vibrational Spectra of Seven Hundred Benzene Derivatives; John Wiley and Sons: New York, 1974. 